The Egyptian Journal of Hospital Medicine (April 2019) Vol. 75 (2), Page 2149-2153

\title{
The Relation between Serum C-Reactive Protein Level and Gestational Diabetes Mohammed Khaled Mostafa ${ }^{1}$, Tamer Fares Ouf ${ }^{1}$, Ahmed Fathy Abd AL- Aziz ${ }^{2}$, Hesham Ahmed Hegazy ${ }^{1^{*}}$ \\ Departments of ${ }^{1}$ Obstetrics \& Gynecology and ${ }^{2}$ Clinical pathology, Faculty of Medicine, Al-Azhar University, Cairo, Egypt \\ *Corresponding author: Hesham Ahmed Hegazy, Mobile: 01008632367, Email: h_a_h_1989@ @otmail.com
}

\begin{abstract}
Background: Gestational diabetes is one of the most common medical condition during pregnancy and its early detection is necessary to prevent prenatal and maternal complications. There is a link between raised CRP and development of gestational diabetes, so early detection of raised CRP may avoid serious maternal and neonatal hazards. Objective: The goal of this study was to detect the prevalence of raised high sensitivity C- reactive protein (hs- CRP) in normal pregnancy and gestational diabetes mellitus (GDM) and to compare the prevalence in both groups. Materials and methods: A case-control study was conducted between April 2018 and December 2018. A number of 60 pregnant women who were investigated for oral glucose tolerance test at 24-28 weeks of gestation were enrolled in this study. They were divided into 30 women with GDM as cases and 30 normal pregnant as control. They were investigated for the level of hs- CRP. Results: The prevalence of elevated hs- CRP in controls was $60 \%$, whereas in cases it was $83.3 \%$, with a $P=0.045$ which is significant in this study.

Conclusion: The study showed a raised level of hs- CRP in GDM in comparison with normal pregnant subjects.

Keywords: C-reactive protein, gestational diabetes.
\end{abstract}

\section{INTRODUCTION}

Inflammation is a basic component for a successful pregnancy ${ }^{(1)}$. Without a doubt, inflammatory processes are associated with implantation and decidualization during early periods of gestation, yet additionally in the uterine activation during delivery ${ }^{(1-}$ ${ }^{3)}$. Nonetheless, during the mid-gestation a quiescence of inflammation is needed to ensure maternal tolerance for fetal antigens (4). A growing body of evidence assumes that a dysregulated maternal inflammation during gestation may be a conceivable risk factor for several neonatal complications ${ }^{(5,6)}$. In addition, a few studies have showed a connection between inflammation and the advancement of gestational complications ${ }^{(7,8)}$. The detection of an inflammatory biomarker with low cost, easy to be measured and able to predict high risk pregnancy might allow a better screening during gestation.

There is an insulin resistance during ordinary pregnancy, which is further improved in pregnancy complications. For example, GDM, disturbed placental function, preeclampsia and IUGR ${ }^{(9)}$. There has been a relationship between hs-CRP and pregnancy related complications ${ }^{(10)}$. The significance of estimating maternal circulating hs-CRP in diagnosing of subclinical infection as well as inflammation in ladies with preterm rupture of membrane ${ }^{(11)}$ in anticipating the danger of preterm labor ${ }^{(12)}$ and preeclampsia ${ }^{(13)}$ has been discussed by some researches. As most pregnancy complications show up in later period of pregnancy but underlying pathophysiology begins early in pregnancy subsequently, an early hs-CRP determination may help in the detection of unfavorable pregnancy result. The level of hs-CRP gives a better sensitivity in establishing inflammation than levels of C-reactive protein (CRP) (14). Pregnancy is a hyperglycemic interval of life and is related with increasing insulin resistance beginning at midgestation ${ }^{(15)}$. In GDM, an increased severity of insulin resistance can disturb the intrauterine milieu, prompting abnormal fetal growth ${ }^{(16)}$. When increased insulin release can't adjust for the pregnancy-initiated insulin resistance then GDM results ${ }^{(17)}$.

The present study was conducted to examine the prevalence of elevated hs-CRP, an oxidative stress biomarker and acute phase reactant in normal pregnancy and GDM. In this study, IADPSG criteria were taken for diagnosis of GDM.

\section{MATERIALS AND METHODS \\ Study design:}

The study was a case control study to evaluate the relation between gestational diabetes and C-reactive protein (CRP) at 24-28 weeks of gestation.

Study period:

April 2018 to December 2018.

\section{Study setting:}

The study was conducted on sixty pregnant patients in Antenatal Unit in Al-Azhar University Hospitals and Etay Al-Baroud general Hospital. After approval of the Medical Ethics Committee and signing a written informed consent.

The patients were divided into two groups:

- $\quad \operatorname{Group}(\mathrm{A}): 30$ pregnant females diagnosed with gestational diabetes.

- $\quad$ Group (B): 30 normal pregnant females.

Inclusion criteria:

1) Maternal age: $20-40$ years old.

2) Singleton pregnancy.

3) Gestational age: $24^{\text {th }}-28^{\text {th }}$ weeks.

Exclusion criteria:

1) Diabetes mellitus.

2) Chronic inflammatory diseases. 
3) Pre-existing history of Hypertension.

4) Active infectious diseases e.g. viral hepatitis, tuberculosis, syphilis.

5) Autoimmune diseases.

6) Nearby use of NSAIDs.

\section{Data collection technique and tools:}

Those women enrolled in this study, underwent screening test with oral glucose tolerance test (OGTT) at 24-28 weeks of gestation. Full explanation was given to the study subjects in a language preferred by them. Those subjects who accepted to participate in the study gave a verbal and informed written consent. During the study, each participant's demographic data such as age, gender, address was noted in the pro- forma. A detailed present, past, and obstetric history was taken followed by general and systemic examinations with relevant investigations. After initial investigations, women with impaired OGTT were diagnosed as GDM. Then, a baseline hs- CRP was done in both normal pregnancy and GDM which could be normal or elevated. We classified them into two groups (case and control) based on serum hs- CRP level. A reference value of hs- CRP concentration below $3 \mathrm{mg} / \mathrm{L}$ is considered normal for this study.[15]

1. Case- serum hs- CRP level above or equal to $3 \mathrm{mg} / \mathrm{L}$.

2. Control- serum hs- CRP level below $3 \mathrm{mg} / \mathrm{L}$.

Parameters of patients including parity, period of gestation, vitals, height, weight, body mass index (BMI), and OGTT were recorded as observational data.

At the end prevalence of elevated hs- CRP was determined in both cases and control then prevalence of elevated hs- CRP was compared in both of cases and control.

\section{RESULTS}

Serum level of hs- CRP was done in all patients. Mean value of hs- CRP in control and cases were compared and a $\mathrm{P}<0.001$, which is significant in this study as shown in table (1) and figure (1).

Table (1): Comparison between the two studied groups according to CRP

\begin{tabular}{||l|l|l|l|l|l||}
\hline \hline \multirow{2}{*}{ CRP } & \multicolumn{2}{l|}{$\begin{array}{l}\text { Group A } \\
(\mathbf{n = 3 0})\end{array}$} & \multicolumn{2}{l|}{$\begin{array}{l}\text { Group B } \\
(\mathbf{n = 3 0})\end{array}$} & \multirow{2}{*||}{} \\
\cline { 2 - 6 } & No. & \% & No. & \% & \\
\hline$<3$ & 5 & 16.7 & 12 & 40 & $0.045^{*}$ \\
$\geq 3$ & 25 & 83.3 & 18 & 60 & \\
\hline Min. - Max. & $1.50-14.0$ & $0.90-8.0$ & \\
Mean \pm SD. & $7.26 \pm 3.64$ & $3.84 \pm 2.22$ & $<0.001^{*}$ \\
Median & 7.75 & 3.4 & \\
\hline
\end{tabular}

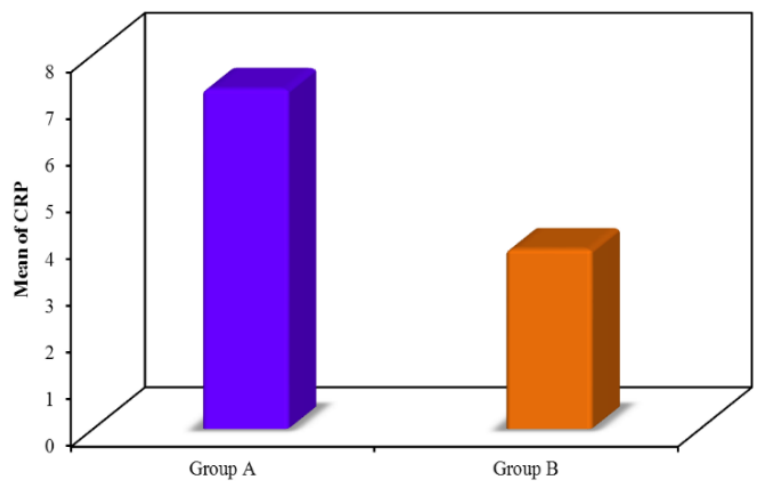

Figure (1): Comparison between the two studied groups according to CRP.

The prevalence of elevated hs- CRP ( $\geq 3 \mathrm{mg} / \mathrm{L})$ in controls was $60 \%$ whereas in cases is $83.3 \%$, whereas hs- CRP $(<3 \mathrm{md} / \mathrm{L})$ was seen in $40 \%$ of controls and $16.7 \%$ of cases, with a $\mathrm{P}=0.045$ which is significant in this study.

Thus, it was observed that the prevalence of elevated hs- CRP ( $\geq 3 \mathrm{mg} / \mathrm{L}$ ) was significantly higher in cases as compared to controls $(\mathrm{P}=0.045)$ as shown in Table (1).

Table (2): Relation between CRP and Age in each group

\begin{tabular}{|l|c|c|c|}
\hline \multirow{2}{*}{ Age } & \multicolumn{2}{|c|}{ CRP } & \multirow{2}{*}{ p } \\
\cline { 2 - 3 } & $<\mathbf{3}$ & $\geq \mathbf{3}$ & \\
\hline Group A & $(\mathbf{n = 5})$ & $(\mathbf{n = 2 5})$ & \\
$\leq 25$ & $1(3.3 \%)$ & $11(36.6 \%)$ & \multirow{2}{*}{0.622} \\
$>25$ & $4(13.3 \%)$ & $14(46.6 \%)$ & \\
\hline Group B & $(\mathbf{n = 1 2 )}$ & $(\mathbf{n = 1 8})$ & \\
$\leq 25$ & $5(16.6 \%)$ & $8(26.6 \%)$ & \multirow{2}{*}{1} \\
$>25$ & $7(23.3 \%)$ & $10(33.3 \%)$ & \\
\hline
\end{tabular}

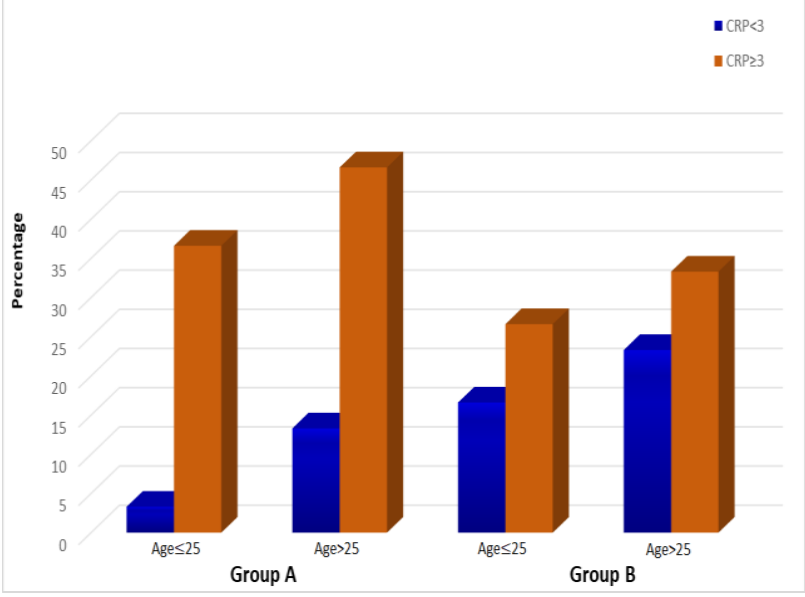

Figure (2): Relation between CRP and Age in each group 
In this study, it was observed that the level of hs- CRP ( $\geq 3 \mathrm{mg} / \mathrm{L}$ ) when compared to age, BMI, and gravida in controls, a $\mathrm{P}=1.000$ for age, and 0.066 for gravida was obtained which was not significantly associated with age and gravid state in controls. While, $\mathrm{p}$ value was $<0.001$ for BMI which was significant that indicates elevated hs- CRP levels in relation with BMI, as shown in tables $(2,3 \& 4)$ and figures $(2,3 \& 4)$.

The association of elevated hs- CRP ( $\geq 3 \mathrm{mg} / \mathrm{L})$ in cases with age, BMI, and gravid state was observed and it was found that age, $\mathrm{BMI}$ and gravida had a $\mathrm{P}=$ $0.6221,0.258$ and 1.000 , respectively which was not significantly associated with the level of hs- CRP $(\geq 3$ $\mathrm{mg} / \mathrm{L})$ as shown in tables $(2,3 \& 4)$ and figures $(2,3 \&$ 4). In our study, mean gestational age was $26.67 \pm 4.18$ in control and $28.27 \pm 4.59$ in cases with a $\mathrm{P}=0.163$ which was not significant.

Table (3): Relation between CRP and BMI $\left(\mathrm{kg} / \mathrm{m}^{2}\right)$ in each group

\begin{tabular}{|c|c|c|c|}
\hline \multirow{2}{*}{$\begin{array}{c}\text { BMI } \\
\left(\mathrm{kg} / \mathrm{m}^{2}\right)\end{array}$} & \multicolumn{2}{|c|}{ CRP } & \multirow{2}{*}{$\mathbf{p}$} \\
\hline & $<3$ & $\geq 3$ & \\
\hline Group A & $(\mathbf{n}=5)$ & $(n=25)$ & \multirow{4}{*}{0.258} \\
\hline Min. - Max. & $22.58-30.44$ & $23.0-33.0$ & \\
\hline Mean \pm SD & $26.51 \pm 3.02$ & $28.25 \pm 3.08$ & \\
\hline Median & 27.29 & 28.73 & \\
\hline Group B & $(n=12)$ & $(n=18)$ & \multirow{4}{*}{$<0.001^{*}$} \\
\hline Min. - Max. & $20.20-29.70$ & $20.23-33.80$ & \\
\hline Mean \pm SD. & $23.86 \pm 2.47$ & $28.87 \pm 3.65$ & \\
\hline Median & 24.33 & 29.17 & \\
\hline
\end{tabular}

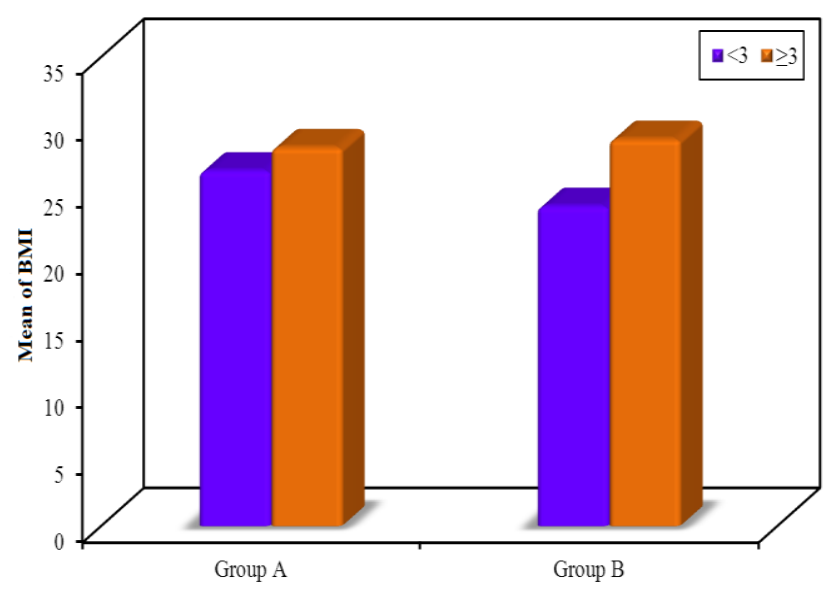

Figure (3): Relation between CRP and BMI $\left(\mathrm{kg} / \mathrm{m}^{2}\right)$ in each group.

The prevalence of primigravida in control is $16.7 \%$ and $10 \%$ in cases whereas the prevalence of multigravida in control is $83.3 \%$ in control and $90 \%$ in cases with a $\mathrm{P}=0.706$ which shows that there was no significant difference in gravid state between cases and controls.
Table (4): Relation between CRP and gravidity in each group

\begin{tabular}{|c|c|c|c|c|c|}
\hline \multirow{3}{*}{ Gravidity } & \multicolumn{4}{|c|}{ CRP } & \multirow[t]{3}{*}{${ }^{{ }^{F E}} \mathbf{p}$} \\
\hline & \multicolumn{2}{|c|}{$<3$} & \multicolumn{2}{|c|}{$\geq \mathbf{3}$} & \\
\hline & No. & $\%$ & No. & $\%$ & \\
\hline Group A & \multicolumn{2}{|c|}{$(n=5)$} & \multicolumn{2}{|c|}{$(n=25)$} & \multirow{3}{*}{1.000} \\
\hline Primi & 0 & 0.0 & 3 & 12.0 & \\
\hline Multi & 5 & 100.0 & & 88.0 & \\
\hline Group B & \multicolumn{2}{|c|}{$(n=12)$} & \multicolumn{2}{|c|}{$(\mathrm{n}=18)$} & \\
\hline Primi & 0 & 0.0 & 5 & 27.8 & 0.066 \\
\hline Multi & 12 & 100.0 & 13 & 72.2 & \\
\hline
\end{tabular}

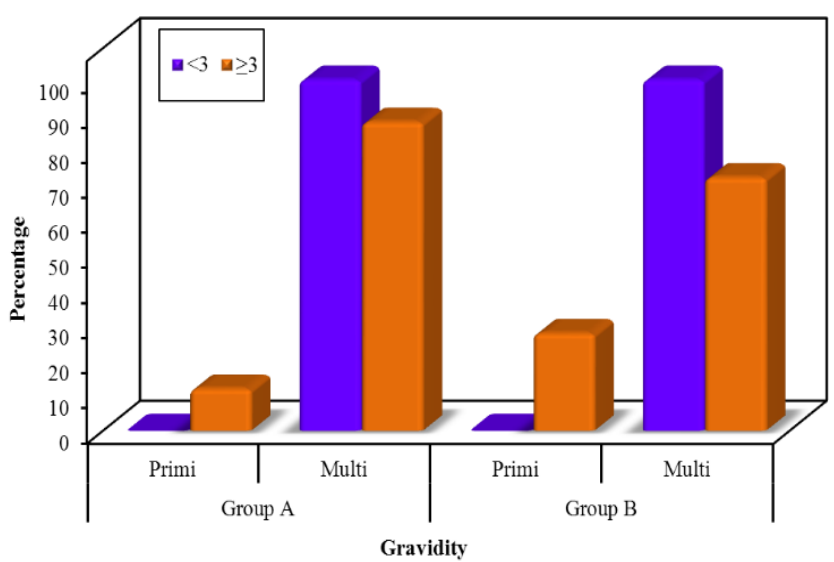

Figure (4): Relation between CRP and gravidity in each group

\section{DISCUSSION}

Gestational diabetes is formally defined as "any degree of glucose intolerance with onset or first recognition during pregnancy". This definition recognizes the likelihood that patients may have already undiscovered diabetes mellitus, or may have developed diabetes incidentally with pregnancy. Regardless of whether manifestations subside after pregnancy is likewise unessential to the finding ${ }^{(18)}$. Recently, the American Diabetes Association (ADA re-defined GDM as follows: "diabetes diagnosed in the second or third trimester of pregnancy that was not clearly overt diabetes prior to gestation" ${ }^{(19)}$.

C-reactive protein (CRP), the predominant and sensitive marker in acute phase response, elevates obviously during acute inflammation, trauma and other diseases ${ }^{(20)}$. Its synthesis is regulated by activated monocyte, fibroblast and some cytokines such as interleukin (IL) especially IL-6, tumor necrosis factor $(\mathrm{TNF}-\alpha)$ and transforming growth factor (TGF- $\beta)^{(21)}$. Increasing evidences support that there are distinct degrees of subclinical inflammation in women with GDM and inflammation effect, which plays an important role in the process from insulin resistance to gestational diabetes mellitus ${ }^{(22)}$. The aim of the work was to study the association between C-reactive protein level and the development of gestational diabetes.The study included sixty pregnant women in Antenatal Unit, 
Al-Azhar University Hospitals and Etay Al-Baroud General Hospital. Patients were classified into two groups: group (A):30 women with gestational diabetes and group (B):30 normal pregnant females. In the present study patients were subjected to $100 \mathrm{gm}$ oral glucose tolerance test to confirm diagnosis of GDM and serum C - reactive protein level were measured. The results of the present study showed that, there were no statistically significant differences between the two groups concerning age, gravidity, parity, gestational age, BMI, systolic and diastolic blood pressure.

The result of the study showed that serum CRP levels in the GDM group were higher than those in the control group. The CRP of the two studied groups showed statistically significant differences with a mean of $7.26 \pm 3.64 \mathrm{mg} / \mathrm{dl}$ and $3.84 \pm 2.22 \mathrm{mg} / \mathrm{dl}$ in cases and normal groups respectively. These data indicated that elevated CRP levels were associated with a high risk of developing GDM.The association of elevated hs- CRP $(\geq 3 \mathrm{mg} / \mathrm{L}$ ) in group (B) with BMI was observed and it was found that BMI had a $\mathrm{P}<0.001$, which was significantly associated with the level of hs- CRP ( $\geq 3$ $\mathrm{mg} / \mathrm{L}$ ) in comparison with group (A) which was not significant.

In support of our result is the study of Renu and Harkaran ${ }^{(23)}$ who studied the relationship between gestational diabetes and CRP. The prevalence of elevated hs- CRP $(\geq 3 \mathrm{mg} / \mathrm{L})$ in controls was $28 \%$ whereas in cases was $76 \%$, whereas hs- CRP $(<3 \mathrm{md} / \mathrm{L})$ was seen in $72 \%$ of controls and $24 \%$ of cases, with a $P$ $=0.002$, which is significant in this study. Thus, it was observed that the prevalence of elevated hs- CRP $(\geq 3$ $\mathrm{mg} / \mathrm{L}$ ) was significantly high in cases as compared to controls $(\mathrm{P}=0.002)$. In this study, it was observed that prevalence of $\mathrm{BMI}<23$ was $32 \%$ in controls and $8 \%$ in cases whereas BMI > 23 was $68 \%$ in control and $92 \%$ in cases with a $\mathrm{P}=0.044$ which is significant.

In a prospective study directed by Qiu et al. ${ }^{(24)}$ to analyze the relationship among CRP and GDM risk. Ladies were enrolled before 16 weeks of gestation and were followed until delivery. This study exhibited that raised CRP was related with GDM risk. After adjustment of maternal pre-pregnancy BMI, family history of diabetes and nulliparity women with CRP in the most elevated tertile encountered a 3.5- fold increased risk of GDM (95\% CI 1.2-9.8) as contrasted with those in the least tertile. The relationship among CRP and GDM was clear when examinations were confined to lean ladies (BMI $<25 \mathrm{~kg} / \mathrm{m} 2$ ). Lean ladies with CRP $\geq 5.3 \mathrm{mg} / \mathrm{l}$ had a 3.7 - fold increased risk of GDM (95\% CI 1.6-8.7) as contrasted with ladies with CRP $<5.3 \mathrm{mg} / \mathrm{l}$. This study concluded that systemic inflammation is associated with an increased risk of GDM and this correlation is autonomous of maternal pre-pregnancy adiposity.

Rota, et al. ${ }^{(25)}$ assessed the correlation between low-grade systemic inflammation expressed as C- reactive protein and gestational diabetes in non-obese pregnant women. This study included 20 non-obese pregnant ladies with gestational diabetes mellitus and 30 non-obese pregnant ladies without gestational diabetes mellitus as a control gathering. The body mass indices of all the subjects were $<25 \mathrm{~kg} / \mathrm{m} 2$. During 2628 gestational weeks, 100 -g oral glucose tolerance test was done and fasting C-reactive protein levels were estimated. Serum median C-reactive protein level was higher in ladies with gestational diabetes mellitus $(\mathrm{p}=$ $0.0001)$. C-reactive protein was strongly connected with glycemic parameters and weight gain during pregnancy. A model comprising of glucose intolerance, age, parity, and weight gain during pregnancy represented $61 \%$ of the fluctuation in level of C-reactive protein. Their study exhibited that serum C-reactive protein level was related with gestational diabetes mellitus and weight gain during pregnancy in late second and early third trimesters.

Our result is partially opposing the report of Rentankaran et al. (26) likewise which exhibited that maternal serum levels of CRP are not related to GDM at the time of oral glucose tolerance testing in late second or early third trimester. A cross-sectional study to decide if markers of subclinical inflammation are raised in patients with GDM. 180 healthy pregnant ladies experiencing oral glucose tolerance testing in the late second or early third trimester. Based on oral glucose tolerance testing and pre-pregnancy body mass index (BMI), members were classified into four groups: 1) normal glucose tolerance (NGT) lean (BMI, <25 $\left.\mathrm{kg} / \mathrm{m} 2)\left(\mathrm{n}_{\text {_ }} 65\right) .2\right)$ NGT overweight $\left(\mathrm{n}_{-}\right.$28). 3) impaired glucose tolerance ( $\left.n_{-} 39\right)$ and 4) GDM (n 48). Median CRP level was most elevated in overweight NGT subjects $(8.8 \mathrm{mg} / \mathrm{liter})$, trailed by GDM $(5.5$ $\mathrm{mg} /$ liter), impaired glucose tolerance ( $4.4 \mathrm{mg} / \mathrm{liter})$, and lean NGT (4.4 mg/liter) (overall $P_{-}$0.0297). CRP was significantly associated with prepregnancy BMI $\left(\mathrm{r}_{-}\right.$ $0.38, \mathrm{P}<0.0001)$, followed by fasting insulin $\left(\mathrm{r}_{-} 0.27\right.$, $\left.\mathrm{P}_{-} 0.0002\right)$ and fasting blood glucose $\left(\mathrm{r}_{-} 0.18, \mathrm{P}_{-}\right.$ 0.016). In multivariate direct relapse examination, prepregnancy BMI rose as the most imperative determinant of CRP concentration, while glycemic tolerance status was not a significant factor. Moreover, the watched stepwise increase in CRP per tertile of prepregnancy BMI was not significantly attenuated by glycemic tolerance status or factors known to be related with GDM, Showing that maternal serum levels of CRP are not related to GDM but instead correlate significantly with prepregnancy obesity. These data propose a model in which obesity mediates a systemic inflammatory response, with possible downstream metabolic sequelae, including insulin resistance and glucose dysregulation.

\section{CONCLUSION}

The identification of pregnancies at risk for preventable natal, prenatal and postnatal morbidity and 
mortality is a primary goal of the obstetric care provider. The purpose of this work was to study the relation between elevated serum $\mathrm{C}$ - reactive protein level and gestational diabetes.In the present study, all pregnant females in the second trimester between 24-28 weeks' gestation underwent estimation of $100 \mathrm{gm}$ oral glucose tolerance test and high sensitive serum Creactive protein level.In the present study, there was highly statistical significant relation between serum Creactive protein level and gestational diabetes, with a mean CRP $7.26 \pm 3.64 \mathrm{mg} / 1$ and $3.84 \pm 2.22 \mathrm{mg} / \mathrm{l}$ in pregnant women with gestational diabetes and control group respectively. In this study, it was concluded that high serum C-reactive protein level is associated with the occurrence of gestational diabetes.

\section{RECOMMENDATIONS}

- Diagnostic tests for GDM are highly recommended to be done for all pregnant women with high serum $\mathrm{C}$ reactive protein level.

- C reactive protein is suggested to be done as routine investigation.

- Furthermore studies on large number of patients are warranted to confirm the association between high CRP level and the development of gestational diabetes mellitus and to establish a cut off level.

- Further studies are also recommended on non-pregnant population to evaluate the level of CRP and the development of type 2 diabetes mellitus.

\section{REFERENCES}

1. Chavan A R, Griffith $O \mathbf{W}$, Wagner $\mathbf{G} P$ (2017): The inflammation paradox in the evolution of mammalian pregnancy: turning a foe into a friend. Current Opinion in Genetics \& Development, 47: 24-32, 2017.

2. Erlebacher A (2013): Immunology of the maternal-fetal interface. Annual Review of Immunology, 31: 387-411.

3. Romero R, Espinoza J, Gonçalves L F, Kusanovic J P, Friel L A, Nien J K (2006): Inflammation in preterm and term labour and delivery. Seminars in Fetal and Neonatal Medicine, 11 (5): 317-326.

4. Ferreira $L$ M , Meissner T B, Tilburgs $T$, Strominger $L$ (2017): HLA-G: At the Interface of Maternal-Fetal Tolerance.Trends in Immunology, 38 (4): 272-286.

5. Ginsberg Y, Khatib N, Weiner Z, Beloosesky R (2017): Maternal Inflammation, Fetal Brain Implications and Suggested Neuroprotection: A Summary of 10 Years of Research in Animal Models. Rambam Maimonides Medical Journal, 8 (2): e0028.

6. Boyle A K, .Rinaldi S F, Norman J E, Stock S J (2017): Preterm birth: Inflammation, fetal injury and treatment strategies. Journal of Reproductive Immunology, 119: 62-66

7. Mihu D, Razvan C, Malutan A, Mihaela C (2015): "Evaluation of maternal systemic inflammatory response in preeclampsia." Taiwanese Journal of Obstetrics \& Gynecology, 54 (2): 160-166.

8. Udenze I, Amadi C, Awolola N, Makwe C C (2015): The role of cytokines as inflammatory mediators in preeclampsia. Pan African Medical Journal, 20: 219.
9. Briana DD, Malamitsi- Puchner A (2009): Reviews: Adipocytokines in normal and complicated pregnancies. Reprod Sci, 16: 921- 37.

10. Retnakaran R, Hanley AJ, Raif N, Connelly PW, Sermer M, Zinman B C (2003): reactive protein and gestational diabetes: The central role of maternal obesity. J Clin Endocrinol Metab., 88: 3507- 12.

11. Loukovaara MJ, Alfthan HV, Kurki MT, Hiilesmaa VK, Andersson SH (2003): Serum highly sensitive C- reactive protein in preterm premature rupture of membranes. Eur $\mathbf{J}$ Obstet Gynecol Reprod Biol., 110: 26- 8.

12. Hvilsom GB, Thorsen $P$, Jeune B, Bakketeig LS (2002): C- reactive protein: A serological marker for preterm delivery? Acta Obstet Gynecol Scand., 81: 424- 9.

13. Djurovic S, Clausen T, Wergeland R, Brosstad F, Berg $K$, Henriksen $T$ (2002): Absence of enhanced systemic inflammatory response at 18 weeks of gestation in women with subsequent pre- eclampsia. BJOG., 109: 759- 64.

14. Yu H, Rifai N (2000): High- sensitivity C- reactive protein and atherosclerosis: From theory to therapy. Clin Biochem., 33: 601- 10 .

15. Catalano PM, Tyzbir ED, Roman NM, Amini SB, Sims EA (1991): Longitudinal changes in insulin release and insulin resistance in nonobese pregnant women. Am J Obstet Gynecol., 165 (6 Pt 1): 1667- 72.

16. Radaelli T, Varastehpour A, Catalano P, Hauguel- de Mouzon S (2003): Gestational diabetes induces placental genes for chronic stress and inflammatory pathways. Diabetes, 52: 2951- 8.

17. Buchanan TA, Xiang AH (2005): Gestational diabetes mellitus. J Clin Invest., 115: 485- 91.

18. American Diabetes Association(2010): Diagnosis and classification of diabetes mellitus . Diabetes Care, 34( 1): S62-9.

19. American Diabetes Association(2017): Classification and Diagnosis of Diabetes. Diabetes Care, 40 (1): S11-S24.

20. Du Clos TW (2000): Function of C-reactive protein. Ann Med., 32: 274-8.

21. Pick up JC, Maltock MB, Chusney GD, Burt D (1997): NIDDM as a disease of the innate immune system, association of acute phase reactatnts and interleukin-6 with metabolic syndrome X. Diabetologia, 40: 1286-92.

22. Di Benedetto A, Russo GT, Corrado F et al. (2005): Inflammatory markers in women with a recent history of gestational diabetes mellitus. J Endocrinol Inves.t, 28 (1): 34 8.

23. Kumari R, Singh H (2017): The prevalence of elevated high-sensitivity C-reactive protein in normal pregnancy and gestational diabetes mellitus. J Family Med Prim Care, 6(2): 259- 264.

24. Qiu C, Sorensen TK, Luthy DA, Williams MA (2004): A prospective study of maternal serum $\mathrm{C}$ reactive protein (CRP) concentrations and risk of gestational diabetes mellitus. Paediatr Perinat Epidemiol., 18 (5): 377-84.

25. Rota S, Yildirim B, Kaleli B, Aybek H, Duman K, Kaptanoglu B (2005): C-reactive protein levels in nonobese pregnant women with gestational diabetes. Tohoku $\mathbf{J}$ Exp Med., 206 (4): 341-5.

26. Retnakaran R, Hanley AJG, Raif N, Connelly PW, Sermer M, Zinman B (2003): C-reactive protein and gestational diabetes: the central role of maternal obesity. J Clin Endocrinol Metabol., 88 (8): 3507-12. 